\title{
Continuance Intention to Use Self-Service Technology of Mass Rapid Transit System in Thailand: A Conceptual Framework
}

\author{
Natthakarn Chanmatakulvat and Singha Chaveesuk ${ }^{+}$ \\ King Mongkut’s Institute of Technology Ladkrabang Business School, Bangkok, Thailand
}

\begin{abstract}
In the era of globalization, the emerging relationship of the world's economies, societies, and populaces are realized by interexchange of ventures, innovation, and stream of individuals and data. In terms of innovation, it has assumed a noteworthy job under computerized time in different viewpoints. Particularly, when the technology is carried out, it can create immense transformation in improving the people's living standards for everyday comforts and how organizations arrange their business forms. At presents, several organizations are concentrating on technology adoption to develop strong competencies in the industry and giving powerful emphasis on customer's needs and fulfillment to maintain their loyalty. Within the worldwide service industry, Mass Rapid Transit is one of the biggest transport services which applies technology to enhance operation's quality and service in various perspectives. To serve such principles and demands, self-service technology is implemented significantly. This mechanical function provides new progressive idea of giving service with incredible support of advancement without human association. Ticket vending machine, automated top-up machine, and self-service storage with RFID technology and QR scan code installed at Mass Rapid Transit station in Thailand will be reasonably selected as pilot selfadministration innovations for this research. By this regard, the main purpose of this study is to construct the conceptual framework based on the Information System Success Model (IS Success Model) as the main theory and support with other variables from other theories namely, Performance Expectancy and Social Influence from UTAUT and Continuance Intention to Use from ECM to study on factors that influence on user satisfaction and proceeded with use of self-service technology. Ultimately, the result from conceptual framework will provide the profitable insight into factors that influence continuance intention to use of selfautomated technology at MRT in Thailand. This information can be a guidance for both government and private sector on enhancing their supportive technology service to reach utmost level on customer's needs.
\end{abstract}

Keywords: self-service technology, Information System Success Model, Unified Theory of Acceptance and User of technology, Expectation Confirmation Model, Mass Rapid Transit

\section{Introduction}

It has been beheld that today business industries have evolved drastically. The transformative utilization of Information and Communication Technologies (ICT) and novel interrelated digital systems namely, Internet of Things (IOT), big-data, and artificial intelligence have changed the people's lifestyle and way of conducting commercial activity. Particularly, the advancement in technology will provide both opportunities and challenges for service provider to adapt the business to survive in such monetary circumstances. The trading transformation to reach ultimate-value service has become more and more important that service provider should be aware to be competitive in current industrial condition [1]. With the innovative and digital contribution, service businesses are endeavouring to utilize such benefits on various purposes such as, specific upgrading of service efficiency, reducing of labour cost, and conveying another service method to customer [2]. Self-Service Technology (SST) that allows users to have alternative option to produce service by themselves is one of the most diverse technological associations that becomes a beneficial component of

\footnotetext{
+ Corresponding author. Tel.: +662-329-8461

E-mail address: singha@it.kmitl.ac.th
} 
business administration support. Beatson (1985) stated that SST is a self-automatic linkage which empowers users to mutual conduct activity with computerization rather than a close relationship with service agents [3].

In other words, with SSTs customers do not merely have to confront with an innovation, but also create the service by themselves. This technology is making service exchanges progressively effective, exact, and lively. Self-Service Technology is now executed in many foreign countries for instance, self-fuel filling, hotel self-check-in and out, self-ordering technology, and supermarket kiosk. Similarly, Thailand is starting to develop and use of this technology in various industry especially, in service and hospitality industry. For example, many branches of MK restaurant have been introduced self-service tablet to help customers in ordering food by themselves and Air Asia has utilized self-check-in system via interactive kiosk or online application to support customer on avoiding of airport congestion, long queues, and reducing waiting time to do registration process at the airport [4]. SSTs are substituting many face-to-face service encounters with the intention to make service prosecutions more convenient, quicker, and precise. However, the application of self-service technology into Thai context has some limitations which vary according to the nature of industry which influenced by demographic differences of Thai society, culture, skill, and environment such as, social status, educational level, personal ability, experience, and others [5]. Supportively, Wisuttisaeng (2016) summarized in her study about the factors that limit Thai people to adopt self-service technology which are personality and behaviour of Thai people, restriction in information technology law and regulation, and insufficient support from government [6].

As an industrialized country, Thailand is putting its strong emphasis on various viewpoints to enhance citizen's subsistence. Mobility infrastructure is one of the main important foundations that serves people on their comfortable and convenient journey and lifestyle. Mass Rapid Transit (MRT) is a subsidiary of transportation services. It is high-capacity open vehicle found in metropolitan territory [7] that currently both government and private sectors have spent huge investment on expanding facilities to serve commuters and travelers to keep away from unpleasant journey among traffic gridlock [8]. The yearly report of Mass Rapid Transit Authority of Thailand in 2019 presented that the number of ridership has been continually increasing every year [9]. Therefore, to serve passenger in the view of overall service quality with increasing of productivity, MRT business providers are giving more consideration on innovative adoption to magnetize people to use this sort of transport. The self-service technology is determined not only helping user in numerous aspects, but also bringing many positive changes in transport business itself by minimizing operation and worker cost whereas maximizing organization's profit. However, the study of continuance intention to use of self-service technology in term of transportation business is not widely conducted, especially in Thailand.

Therefore, by conducting this study, the researcher will focus on self-service technology installed at MRT service area such as, ticket vending machine, automated top-up machine, and self-service storage with RFID technology and QR scan code as pilot innovation that can be reached out to study in different industries. To approach the study objectives, the researcher develop a conceptual framework with constructs of IS success model (Information quality, System quality, Service quality, and User satisfaction) as the principle structure and partial variables from UTAUT (Performance expectancy and Social influence) and ECM (Continuance intention to use) to empirically investigate how the information system factors and environmental factors influences on user continuance usage intention of self-service technology of Mass Rapid Transit (MRT) system in Thailand.

This paper is organized as follows. Section 2 describes the background and theories of this research. Section 3 presents the conceptual framework, relationship, and hypotheses. Finally, Section 4 discusses the contribution and future work of this research.

\section{Background and Theories}

This section explains the background and examples of self-service technology and the theories of Information System Success Model (IS Success Model), Expectation Confirmation Model (ECM), and Unified Theory of Acceptance and Use of Technology (UTAUT). 


\subsection{Self-Service Technology and Examples}

Self-Service Technology (SST) or Technology-Based Self-Service (TBSS) can be characterized as mechanical interface that empowers users to deliver independent service from direct service work inclusion [10]. SSTs have confirmed an advance innovation in making life more comfortable and convenient for people in various circumstances. It also plays a vital part in reducing time and effort from many parts of our daily lives [2]. In the most recent decade, Mass Rapid Transit (MRT) system in Thailand providers have been considered implementing of self-service technologies to overcome economy situation such as lessening overhead expense while increasing their productivity [2]. There are numerous examples of SST which have been employed in the service area.

Ticket Vending Machine (TVM) and Automated top-up machine are technologies that were utilized for Mass Rapid Transit service for a decade; however, the systematic functions of these machines are continuously improving to keep up-to-date. The additional functions such as Radio Frequency Identification scanning and QR code scan is included. The user can easily buy the ticket and recharge money to be stored value in the contactless card [11]. This technology can encompass services to be a cashless society with offering convenient, secure, and electronic value-added payment not only transportation service but also retails and hospitality services. By using this self-service technology, user can obviously avoid holding up long queue and the situation of interacting with merchant directly which may keep users happy while minimizing the stress of employees. It is also accessible in hours when ticket offices are temporary closed.

Moreover, self-service storage, Lock box, is another self-service innovation which is available at Mass Rapid Transit hubs. This technology is widely getting attention by many travellers. It provides the idea of privately-run locker service that supports the travellers' convenience with no requirement to carry the extra weight during their journey.

\subsection{Information System Success Model (IS Success Model)}

The Information System Success Model (IS Success Model) was firstly proposed by DeLone and McLean in 1992. It has been widely accepted and used as an important guideline in evaluating the quality of information systems in various aspects. DeLone\& McLean (1992) stated that the success of an information system can be measured at three different levels which are (1) Technical level related to measurement of accuracy and system efficiency, (2) Meaning level related to measurement of intention to convey meaning of information, and (3) Effectiveness level related to measurement level of information impact on users [12]. A few years later, DeLone\& McLean developed 1992 model to the latest updated model version which were used in 2003 as shown in the Fig.1.

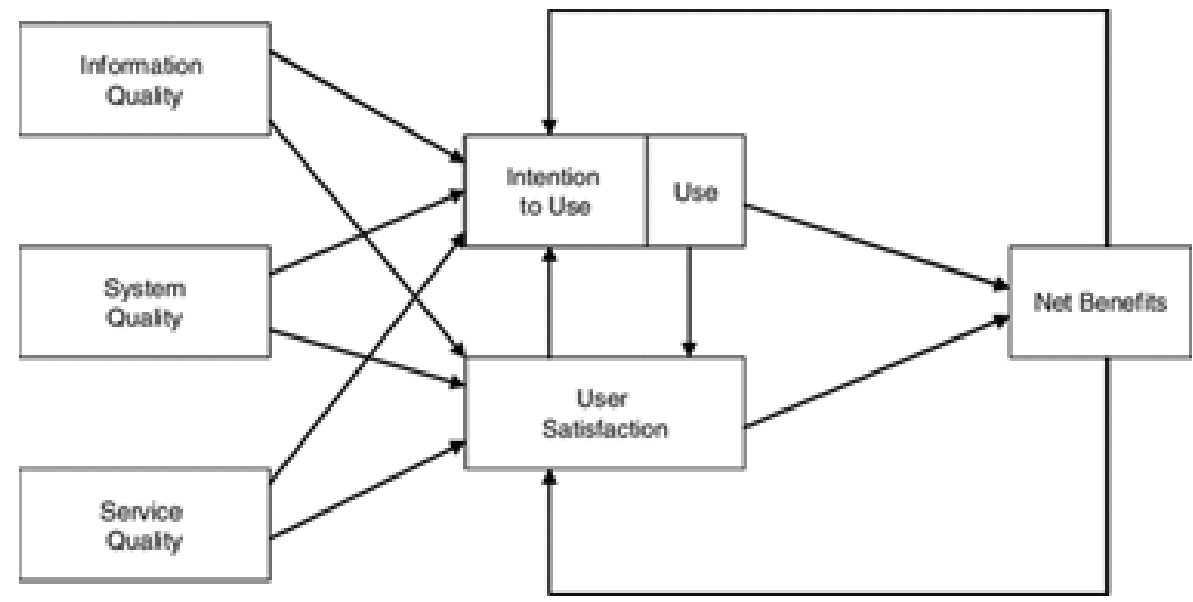

Fig. 1: Ten-year updated of DeLone\& McLean’s IS Success Model in 2003

The final main construct variables of this model are Information quality, System quality, Service quality, Intention to use, Use, User satisfaction, and Net benefits [13]. According to the research conducted by Treerattanachawalit in 2014, her study focuses on the implementation of Home Service Application for own real estate resident in order to resolve the problem related to missing important information for condo service managements and how the residents can track any notifications from them suddenly, conveniently, and completely via smart phone. The research aims to study the factors that influence Home Service Application 
usage. Her main conceptual framework was developed based on the construct of IS Success Model factors. The collection data from 165 residents was validated using of factor analysis and regression analysis. The result revealed that Information quality, System quality, Service quality, User expectation, Extrinsic motivation, and User satisfaction have influences to intention to use. This result explores the main factors which any companies can consider to improve and adjust self-service system in order to meet customer satisfaction with distinct user's lifestyle [14].

\subsection{Expectation Confirmation Model (ECM)}

Bhattacherjee developed and proposed an Expectation Confirmation Model in 2001 in accordance with IS Continuance. This model is used to explain the sequence of user initial use experience and then closely involved with user satisfaction and final making post decision and acceptance to continuing use or reversal of the initial decision. The continuance intention to use can be understood as the intention of user to keep on using information system, service, or product [15]. Previously, the ECM has been widely adopted by numerous researchers to study and verify the user's continuance intention in using of information system and technology. For example, Samar applied ECM to explain about the customer satisfaction evaluation and Information system continuance use related to Internet banking adoption. The study concentrated on postacceptance and post-consumption expectation factors [16]. The study of $\mathrm{Li}$ and Shang in another research, they studied the interrelationship influence citizen's reuse intention regarding e-government based on the ECM factors by collecting the data from 1,650 citizens who had prior experience with e-government service and then testing by structural equation modeling. The result showed that from eight contributing dimensions, perceived service value is a powerful mediator between service quality and citizen's continuous-use intention. Moreover, the intention to use is a consequence of service quality, service value, and satisfaction [17].

\subsection{The Unified Theory of Acceptance and Use of Technology (UTAUT)}

The Unified Theory of Acceptance and Use of Technology (UTAUT) was proposed by Venkatesh et al. in 2003 as an integrated framework of eight related technology acceptance theories. This model was constructed composing of the diffusion of innovation theory, the TRA, the TPB, the motivation theory, the hybrid model of TPB and TAM, the original TAM, the PC utilization model, and the social cognitive theory [18]. UTAUT has been broadly employed by many scholars to understand the adoption of different types of technology from both aspects which are organizations and individuals within different cultural contexts [19],[20]. According to the study of Paul in 2013, the evolution of the internet attracts more and more students to participate in online learning circumstance. The research aims to explore the demand of Taiwanese college students to attend English E-Learning websites. The data was collected from 176 respondents from more than ten Taiwanese colleges and then analysed based on the conceptual framework which constructs from UTAUT. The results demonstrate that performance expectations, effort expectancy, and social influence have positive effects on behaviour intentions and facilitating conditions. Finally, it can be concluded that if students believe that English E-Learning websites are able to assist them increase their performance and that they can use with effortless, there is an increase in their intention to use such websites [21].

\section{Conceptual Framework and Relationships and Hypotheses}

This paper concentrates on developing a conceptual framework from various factors which are quality aspects of technology, user perception, external circumstance that influence on willingness to continue use of self-service technology. The proposed framework is constructed based on the various theories which are IS Success Model, UTAUT, and ECM. The main objective of this study is to provide the insight information into factors that influence user satisfaction and further affect continuance intention to use of self-automated technology of MRT in Thailand.

According to the above explanation of background and theories, the researcher built up the conceptual framework by adopting factors from different theories which are Information quality, System quality, Service quality, User satisfaction from IS Success Model, Performance expectancy and Social influence from UTAUT, and Continuance intention to use from ECM. The framework diagram is presented in Fig 2. 


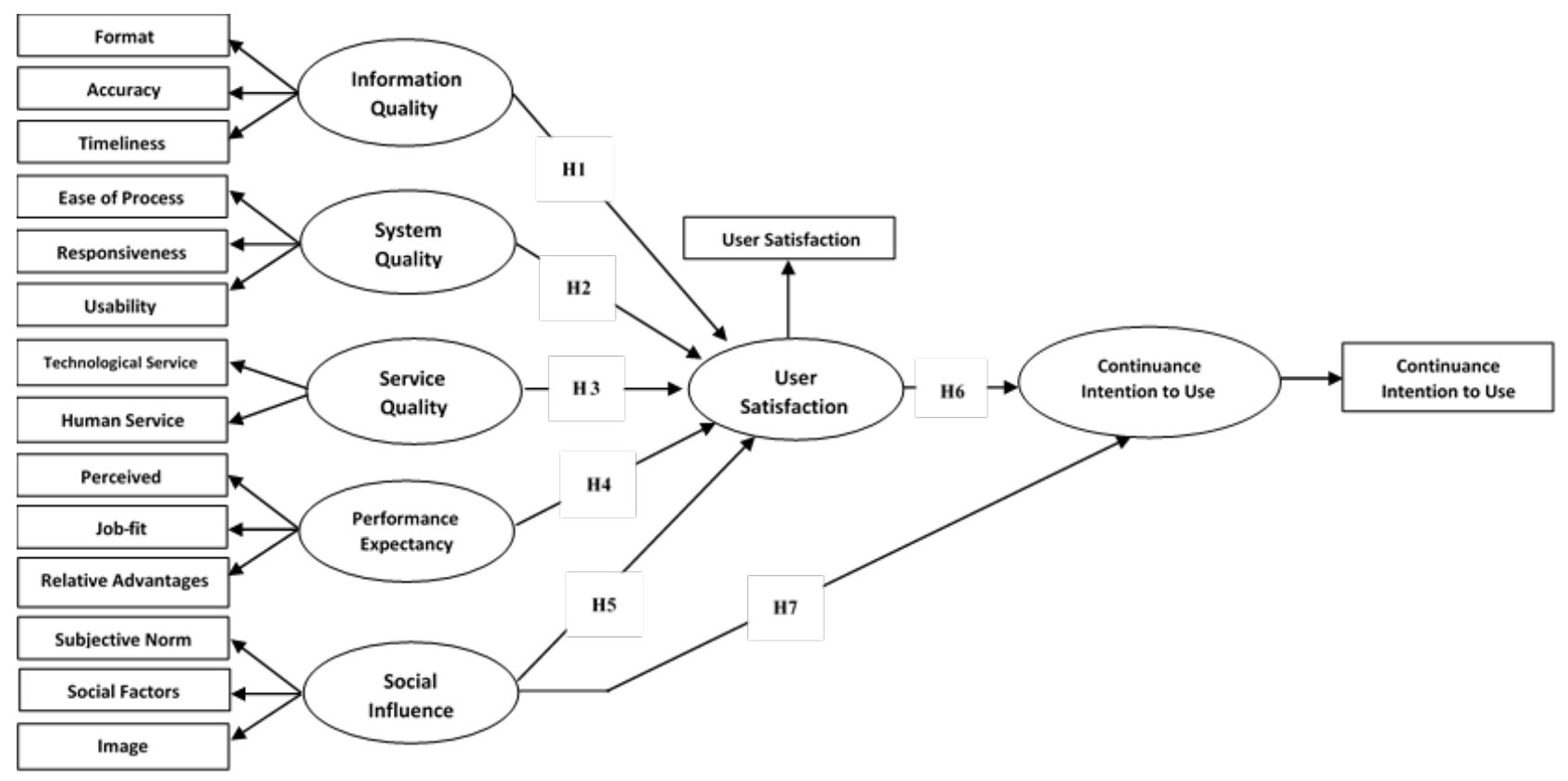

Fig. 2: Conceptual Framework

By this conceptual framework, seven hypotheses are represented the relationship of each variable as follows.

\subsection{Information Quality (IQ), System Quality (SQ), Service Quality (SEQ), and User Satisfaction (US)}

Information quality is one of the significant factors in the success of information system model. It is defined as the quality of the attribute of information and also comprehended as the value of information for particular use [12]. This factor has been widely studied for a decade both in emerging and developed countries to examine the relationship of information quality with others. The research of Garcia and Effken in 2013, they studied the development and evaluation of Information system success model related to medical context. The research reveals that the attributes of information quality which are completeness, accuracy, and format has positive impact on user satisfaction with using of medical information system [22]. Generally, the information quality can be measure in vary dimension such as, format, timeliness, compactness, relevance, accuracy, and others [12].

System quality can be described as the technical quality of the information system itself. It can be measured in various indexes for instance, ease of use, flexibility, responsiveness, functionality, and others. This quality factor is in top level of evaluating on the success of information system since the system quality should be highly reliable and fast interact with the user's command [13]. Supportively, the study of Wang and Chao related to system quality, user satisfaction, and benefits that users gain from mobile network services. The results revealed that the quality of system of 3.5G mobile phone network has positive impact on user satisfaction and then lead to the user benefits [23].

Service quality can be conceptualized as the perceptive understanding of user needs in accordance with the service delivery. People agrees that service quality depends on level of actual service performance that meets users' need and expectation [24]. According to the study of Muhammad Shahid Iqbal and his team, they conducted the research to examine how the self-service technology impact the customer satisfaction, loyalty, and Behavioral Intentions in service sector of Pakistan. The data collection of 238 self-service technology users through the online survey and then the model was tested by SEM via LISREL program. The results showed positive and significant relationship between technology-based service in terms of service quality, loyalty, and behavioral Intentions directly and indirectly via customer satisfaction. In conclusion, these results provide insights for the service sector of the Pakistan to consider investing in the new technology in order to enhance the consumer experience, satisfaction, loyalty, and Intentions [25,26].

In terms of self-service technology, the information quality, system quality, and service quality will be the primary indicators to measure user's contentment. If the users positively perceive of information, system, 
and service quality provided by self-service technology, they may demand to use such technology on a regular basis on a variety of purposes and prefer to use as much as possible. After reviewing previous studies and relevant literature, the following hypotheses have been proposed as follows:

H1: Information Quality has positive influence on User Satisfaction

H2: System Quality has positive influence on User Satisfaction

H3: Service Quality has positive influence on User Satisfaction

\subsection{Performance Expectancy (PE) and User Satisfaction (US)}

Performance expectancy is defined as the degree to which the people believes that using the system will assist them to achieve in job performance. This includes of five constructs which are perceived usefulness, extrinsic motivation, job-fit, relative advantages, and outcome expectations [18]. This variable reflects perceived benefits and utilities that can be expected from self-service technology adoption. This can enhance service performance and efficiency and user's living. Regarding from the research of Madara, the mobile Internet has become one of the most popular mobile services for customers worldwide, reflecting the importance of mobile internet. The study aims to clarify factors that influence mobile Internet adoption and usage in Latvia, especially to determine the current level of mobile Internet use and acceptance. The data collection of 2,000 respondents via e-questionnaires using the Mobile Internet Prevalence Model. The results reveal that performance expectancy, effort expectancy, and facilitating conditions are factors that strongly affected to Behavioral intention in using mobile Internet. It can be summarized that Internet users realize the benefits and options of mobile Internet and then they reuse such service [27]. As the expectation confirmation theory, it explains that when user's expectation and real perception is approved, it will lead to user satisfaction. Therefore, performance expectancy will impact user satisfaction if the users' belief is fulfilled by system assistance. Based on the above clarification, the following research hypothesis was formulated:

H4: Performance Expectancy has positive influence on User Satisfaction

\subsection{Social Influence (SI), User Satisfaction (US), and Continuance Intention to Use (CI)}

Social Influence refers to the way in which people changes their beliefs, revises their opinions, or adapts their behavior to meet the demand of social environment and social interactions with others. As discussed by many researchers, social influence can be counted as a potential determinant of individuals' information system use intention [18]. It can be impacted by both human relations or external stimulation. Particularly, when others who are important to a user suggest him or her to use self-service technology, he or she may conform their recommendations [28]. The human society will compliance to use such technology through the persuasive action. Their decision may be caused by people around them or repeated of advertisement at the service area. Therefore, the trend of adopting self-service technology is becoming popular and then lead to the reuse of that system because of people encouragement. In other words, it is initiated by the process of transferring behavior and ideas of the relevance group in community that like the modernization of technology or think that it is beneficial for them. In this study, the researcher attempts to explore and explain about the social influence caused by people and community to intention to reuse of self-service technology system. The research will be studied both direct and indirect relationship of user satisfaction and continuance intention to use of the system. Hence, the research hypotheses are proposed as follows:

H5: Social Influence has positive influence on User Satisfaction

H7: Social Influence has directly positive influence on Continuance Intention to Use

\subsection{User Satisfaction (US) and Continuance Intention to Use (CI)}

DeLone\& McLean (2003) explained that the user satisfaction means a measure of how satisfied users are with information system [13]. The satisfaction of users is in the influence on recipient level which evaluate the users' decision of system [12]. It is an assessment of how meets or beyond user expectation. Continuance intention to use (CI) can be seen as net benefits of the success of information [15]. When the users perceive that SST supports them in various situations with excellent quality and thus they satisfy against their initial experience, it can lead to continuance intention to use and also its relationship with user satisfaction. 
According to the research conducted by Phalawang in 2018, He studies factors influencing continuance intention to use mobile banking based on IS Success Model, which are Information quality, System quality, and Service quality, and satisfaction, and other factors namely corporate image, security, and customer loyalty. The study aims to determine the determinants that impacts the continuance intention to use of Mbanking. The data was collected from 200 participants who has experience on using mobile banking. The results expose that Continuance intention to use is affected by satisfaction of users which are influenced by corporate image, information quality, and security respectively. This study finally implies entrepreneurs and M-banking developer to realize the important factors which should be applied to improve M-banking for customer usage experience and continuance [29]. Therefore, the research hypothesis is established as follows:

H6: User Satisfaction has directly positive influence on Continuance Intention to Use

\section{Contribution and Future Work}

The aim of this study is to explore how the quality of information system, performance expectancy, and external environment influences the user's continuance intention to use MRT's self-service tech-kiosks in Thailand. This theoretical framework is mainly based on IS Success Model and other supportive theories such as ECM and UTAUT. By this study it will contribute abundant knowledge related to user perception on adopting of SST. A further study will be recommended to empirically investigate and analyse collecting the primary data from people who has experienced of using self-service technology at MRT stations by using questionnaire as a research tool. The target respondents will be approximately 400 people utilizing different sampling technique such as, quota sampling, cluster sampling, and convenience sampling to select the participants from infinite population. The final number of respondents will be complied with SEM's criteria. To answer all hypotheses, the quantitative approach will be applied and validate the model by using numerous analysis methods. The researcher plan to use Index of Item Objective Congruence (IOC) for content validity, Cronbach's alpha for reliability testing, and two-step approaches for statistical analysis which are Confirmatory Factory Analysis (CFA) and Structural Equation Modelling (SEM) via AMOS. However, for the future research, the advance of self-service technology will be examined to understand the customer's perception in different area such as, medical service, educational service, production area, and others. Moreover, the integration of self-service technology with other technologies to upgrade to the advance level namely, full linkage to mobile applications and AR support should be considered, studied, and implemented significantly.

\section{References}

[1] Nantapaiboon, J. (2012). The art of service. Bangkok: V.Print (1991) Co.,Ltd.

[2] Curran, J. M. (2005). Self-service technology adoption: comparing three technologies. Journal of Service Marketing, Vol.19 No.2, 103-113.

[3] Bateson, J. (1985). Self-service consumer: an exploratory study. Journal of Retailing, 49-76.

[4] Nik Abdullah, Nik Ab Halim. (2012). Technology readiness and users satisfaction towards self-service technology at Malaysian airport. Information Management and Business Review. 4. 453-460.

[5] Jakranukul, C. (2015). Perspectives of self-service technology (SSTs) from emerging economy. 2.

[6] Wisuttisaeng, Y. (2016). Executive manager's perspectives of self-service technology in service sector. Bangkok.

[7] UITP (2011). "Recommended basic reference for developing a minimum set of standards for voluntary use in the field of urban rail, according to mandate M/486".

[8] Sathapongpakdee, P. (2017). Mass Rapid transit Operator, Thailand industry outlook 2017-19.

[9] Anwar, Rosiwarna \& Salehudin, Imam \& Mukhlish, Basuki \& Ririh, Kirana. (2017). Intention to Adopt and Willingness to Pay: Mass Rapid Transit (MRT) System in Greater Jakarta, Indonesia. 9.

[10] Lin, J. (2007). The influence of technology readiness on satisfaction and behavioral intentions toward self-service technologies. Computer in Human Behavior, 1597-1615.

[11] Abnewswire (2019, November 22). Passengerticket vending machine (TVM) market 2019 global trend, segmentation and opportunities, forecast 2025. Retrieved from 
https://www.abnewswire.com/pressreleases/passenger-ticket-vending-machine-tvm-market-2019-global-trendsegmentation-and-opportunities-forecast-2025_450806.html on January 15, 2020.

[12] DeLone, W., \& McLean, E. (1992). Information systems success: The quest for the dependent variable. Information Systems Research, 8(3),240-253.

[13] Rai, A., Lang, S., \& Welker, R. (2002). Assessing the validity of IS success models: an empirical test and theoretical analysis. Information Systems Research, 13(1),50-69.

[14] Treerattanachawalit, J. (2014). Factors Effecting Real Estate Residents’ Home Service a Case Study of Sansiri Public Company,Ltd. Independent study. Thammasat University, 3-4.

[15] Bharracherjee, A. (2001b). Understanding information systems continuance: an expectation-confirmation model. MIS quarterly, 25(3),351-370.

[16] Rahi S. and Ghani A. M. (2019). "Integration of expectation confirmation theory and self-determination theory in internet banking continuance intention", Journal of Science and Technology Policy Management. Available: https://doi.org/10.1108/JSTPM-06-2018-0057.

[17] Li, Y., \& Shang, H. (2019). Service quality, perceived value, and citizens’ continuous-use intention regarding egovernment: Empirical evidence from China. Journal of Information\& management.

[18] Venkatesh, V., \& David, F. (2003). User acceptance of information technology: Toward a unified view. MIS Quarterly, 27(3),425-478.

[19] Al-Gahtani, S.S., Hubona, G.S., \& Wang, J. (2007). “Information Technology (IT) in Saudi Arabia: Culture and the Acceptance and Use of IT”. Information \& Management, 44.

[20] Venkatesh V., Thong J.Y., Xu X. (2012). Consumer acceptance and use of information technology: Extending the unified theory of acceptance and use of technology. MIS Quarterly, 36.

[21] Tan, Paul (2013). Applying the UTAUT to Understand Factors Affecting the Use of English E-Learning Websites in Taiwan. SAGE Open.3.10.1177/215824401353887.

[22] Garcia Smith, D., \& Effken, J. (2013). Development and initial evaluation of the Clinical Information Systems Success Model (CISSM). International Journal of Medical Informics, 82(6),539-552.

[23] Wang, E., \& Chao Yu, C. (2011). System quality, user satisfaction, and perceived net benefits of mobile boardband services. In 8th Asia-Pacific Regional ITS Conference. Taipei: International Telecommunications Society.

[24] Grönroos. (1984). A service quality model and its marketing implications. European Journal of Marketing, 36-44.

[25] Iqbal, Muhammad \& Hassan, Masood \& Habibah, Ume. (2018). Impact of self-service technology (SST) service quality on customer loyalty and behavioral intention: The mediating role of customer satisfaction. Cogent Business \& Management. 5. 10.1080/23311975.2018.1423770.

[26] Torkzadeh, G., \& Doll, W. (1999). The development of a tool for measuring the perceived impact of information technology on work. Omega, 27(3),327-339.

[27] Fuksa, Madara. (2013). Mobile Technologies and Services Development Impact on Mobile Internet Usage in Latvia. Procedia Computer Science. 26. 41-50. 10.1016/j.procs.2013.12.006.

[28] Agarwal, R., and Prasad, J. (1997). “A Conceptual and Operational Definition of Personal Innovative-ness in the Domain of Information Technology,” Information Systems Research, 9(2).

[29] Phalawang, T. (2018). Study of Factors Affecting Continuance Usage Intention of M-Banking: Perspectives of Corporate Image \& Application Quality. Journal of Information System Business (JISB), Vol.04, No.04, Oct-Dec, pp.64. 